\title{
PROVA BRASIL, IDEB E ESCOLAS RURAIS DO TERRITÓRIO DO PIEMONTE DA DIAMANTINA- BAHIA: REGULAÇÃO DO TRABALHO DOCENTE NA EDUCAÇÃO RURAL
}

\author{
Elizeu Clementino de Souza (UNEB)* \\ Michael Daian Pacheco Ramos (UNEB)**
}

\begin{abstract}
RESUMO
$\mathrm{O}$ artigo analisa a configuração da regulação do trabalho docente em escolas rurais do Território do Piemonte da Diamantina-Bahia, por meio da aplicação de avaliações externas em larga escala. Investigamos a disposição dos estabelecimentos de ensino da zona rural, do território destacado, na Prova Brasil em 2015 e refletimos sobre seus respectivos Índices de Desenvolvimento da Educação Básica (Ideb). Para isso, realizamos uma pesquisa com caráter documental nas bases de dados do Instituto Nacional de Pesquisa Educacional Anísio Teixeira (Inep). Nossos principais resultados foram: a) há uma maior participação na Prova Brasil 2015, proporcionalmente, de escolas urbanas que de escolas rurais; b) apenas 38\% das escolas rurais do território investigado participaram da Prova Brasil 2015, contudo a disposição da participação no interior dos municípios é diversa e heterogênea; c) um terço das escolas rurais que participaram do exame não obtiveram nota de Ideb; d) um terço das unidades educacionais rurais avaliadas alcançaram a meta e outro um terço não alcançou e; e) nos anos iniciais do ensino fundamental o território apresenta uma disposição positiva no alcance do Ideb entre os anos de 2005 e 2017, contudo, nos anos finais do ensino fundamental será necessário uma maior atenção de alguns municípios.

Palavras-chave: Regulação educativa. Prova Brasil. Avaliação externa. Ideb. Escola rural.
\end{abstract}

\section{ABSTRACT \\ TEST BRASIL, IDEB AND RURAL SCHOOLS IN THE PIAMONTE DIAMANTINA-BAHIA TERRITORY: REGULATION OF TEACHING WORK IN RURAL EDUCATION \\ This article analyze the configuration of the regulation of teaching work in rural schools in the Piedmont Territory of Diamantina-Bahia, through the application of}

\footnotetext{
* Pós-Doutor pela Faculdade de Educação da Universidade de São Paulo (USP). Pós-Doutor (Estágio Sênior) pela Universidade de Paris 13, França. Doutor em Educação pela Universidade Federal da Bahia (UFBA). Professor Titular do Programa de Pós-Graduação em Educação e Contemporaneidade, da Universidade do Estado da Bahia (PPGEduC/UNEB). Coordenador do Grupo de Pesquisa (Auto)biografia, Formação e História Oral (GRAFHO). Pesquisador associado do Laboratoire EXPERICE (Université de Paris 13- Paris 8). E-mail: esclementino@uol.com.br

** Doutorando em Educação pelo Programa de Pós-Graduação em Educação e Contemporaneidade da Universidade do Estado da Bahia (UNEB). Professor do curso de Educação Física da Universidade do Estado da Bahia (UNEB), Campus IV, Jacobina. Pesquisador do Grupo de Pesquisa (Auto)biografia, Formação e História Oral (GRAFHO). E-mail: michaeluneb@gmail.com
} 
external evaluations at large scales. We investigated the disposition of the educational establishments of the rural area, of the highlighted territory, in the Brazil Test in 2015 and we reflected on their respective Basic Education Development Index (Ideb). For this, we conducted a documentary research in the databases of the National Institute of Educational Research Anísio Teixeira (Inep). Our main results were: a) there is a greater participation in the Brazil 2015 Test of the proportion of urban schools than rural schools; b) only $38 \%$ of the rural schools in the territory investigated participated in the Brazil 2015 event, however the disposition of the participation in the interior of the municipalities is diverse and heterogeneous; c) a third of the rural schools that participated in the exam did not obtain Ideb grade; d) one-third of the rural educational units evaluated reached the target and another one-third did not reach e; e) in the initial years of elementary education, the territory has a positive disposition in the scope of Ideb between the years 2005 and 2017, but in the final years of elementary education will require a greater attention of some municipalities.

Keywords: Educational regulation. Proof Brazil. External evaluation. Ideb. Rural school.

\section{RESUMEN}

\section{PROVE BRASIL, IDEB Y ESCUELAS RURALES DEL TERRITORIO DEL PIEMONTE DE LA DIAMANTINA-BAHIA: REGULACIÓN DEL TRABAJO DOCENTE EN LA EDUCACIÓN RURAL}

Este artículo analizar la configuración de la regulación del trabajo docente en escuelas rurales del Territorio del Piamonte de Diamantina-Bahía, a través de la aplicación de evaluaciones externas a gran escala. En el año 2002, se trata de un estudio de la situación de los centros de enseñanza de la zona rural, del territorio destacado, en la Prueba Brasil en 2015 y reflexionamos sobre sus respectivos Índice de Desarrollo de la Educación Básica (Ideb). Para ello, realizamos una investigación con carácter documental en las bases de datos del Instituto Nacional de Investigación Educativa Anísio Teixeira (Inep). Nuestros principales resultados fueron: a) hay una mayor participación en la Prueba Brasil 2015 de la proporción de escuelas urbanas que escuelas rurales; b) sólo el $38 \%$ de las escuelas rurales del territorio investigado participaron en la Prueba Brasil 2015, sin embargo la disposición de la participación en el interior de los municipios es diversa y heterogénea; c) un tercio de las escuelas rurales que participaron del examen no obtuvieron nota de Ideb; d) un tercio de las unidades educativas rurales evaluadas alcanzaron la meta y otros un tercio no alcanzaron y; e) en los años iniciales de la enseñanza fundamental el territorio presenta una disposición positiva en el alcance del Ideb entre los años 2005 a 2017, pero en los años finales de la enseñanza fundamental será necesaria una mayor atención de algunos municipios. Palabras clave: Regulación educativa. Prueba Brasil. Evaluación externa. Ideb. Escuela rural. 


\section{Introdução'}

No Brasil, de acordo com os dados da Pesquisa Nacional de Amostra Domiciliar (Pnad), mais de 5 milhões de pessoas entre 6 e 14 anos vivem na zona rural, onde estão cerca de $33 \%$ de nossas escolas (PESQUISA NACIONAL POR AMOSTRA EM DOMICÍLIO, 2016).

No espaço rural, atualmente existem cerca de 5.573.385 de matrículas na educação básica, que representam cerca de $11,5 \%$ do total do país e estão concentradas, predominantemente, na esfera municipal e nos anos iniciais do ensino fundamental. Nessa localidade temos 345.604 docentes, que representam cerca de $16 \%$ dos professores da educação básica do Brasil (INEP, 2018a). No Brasil, $15 \%$ das turmas estão situadas na zona rural. De acordo com o Censo da Educação básica 2017, no país há 86.333 turmas multisseriadas e grande parte dessas estão localizadas no espaço rural (INSTITUTO NACIONAL DE ESTUDOS E PESQUISAS EDUCACIONAIS ANÍSIO TEIXEIRA, 2018a).

O documento Panorama da Educação do Campo sistematiza desafios relacionados a essas unidades educacionais, os quais são enormes e vão desde a superação da falta de infraestrutura e de professores às elevadas taxas de abandono $\mathrm{e}$ distorção idade-série. O resultado disso é uma população rural acima de 18 anos que passou menos de 9 anos na escola (INSTITUTO NACIONAL DE ESTUDOS E PESQUISAS EDUCACIONAIS ANÍSIO TEIXEIRA, 2007).

Portanto, intentamos notabilizar as desigualdades que caracterizam o sistema educativo brasileiro, nordestino e, em particular, o baiano. Sabemos que em um país heterogêneo como o Brasil, não adianta ver a realidade através das médias, é necessário compreender as peculiaridades que interferem na produção dos extremos e com isso buscar soluções contextualizadas.

1 O texto vincula-se à ação da pesquisa Multisseriação e trabalho docente: diferenças, cotidiano escolar e ritos de passagem (SOUZA, 2013, 2014), financiada pela Fundação de Amparo à Pesquisa do Estado da Bahia (Fapesb) - Edital n0. 028/2012 - Inovação em Práticas Educacionais nas Escolas Públicas da Bahia e do Conselho Nacional de Desenvolvimento Científico e Tecnológico - Edital Universal CNPq - Chamada 14/2014, e As políticas de educação e a reestruturação da profissão docente confrontadas aos desafios da globalização, financiada pela FAPESB, no âmbito do Edital 004/2015 - Cooperação Internacional.
Dessa forma, este artigo tem como foco analisar como vem se constituindo a regulação do trabalho docente em escolas rurais do Território de Identidade do Piemonte da Diamantina-Bahia, por meio da aplicação de avaliações externas em larga escala.

Temos visto ultimamente uma intensificação do processo de regulação do trabalho docente, principalmente através da aplicação e acompanhamento das avaliações em larga escala, sejam elas nacionais, como a Prova Brasil, sejam internacionais, como o PISA e a TALIS. ${ }^{2}$

O processo de reestruturação do capitalismo, principalmente após as reformas da década de 1990, acarretou a constituição de um Estado mais regulador, salientando um discurso da necessidade de mais eficiência e eficácia do setor público. Essa forma de regulação, especialmente no campo educacional, tem atuado em três dimensões: a gestão, o financiamento e a avaliação sistêmica.

Dessa forma, o Estado se constitui em duas facetas: de um lado é ínfimo em seu financiamento, de outro é máximo em sua fiscalização e avaliação. Portanto, diante desse quadro, ganha centralidade as avaliações em larga escala no campo educacional, pois elas irão interferir na gestão, no financiamento e também no próprio trabalho docente.

Essas políticas educacionais caracterizam-se em uma forma de regulação educativa denominada de "obrigação de resultados", compreendendo uma série de intervenções capaz de medir e controlar, com o objetivo de obter maior eficácia escolar.

Diversos pesquisadores, entres os quais podemos destacar Barroso (2003), Oliveira (2004), Afonso (2009), Augusto (2012) e Alves e Soares (2013), vêm desenvolvendo reflexões sobre os impactos e interferências das avaliações em larga escala, das políticas de accontabillity ou "obrigação

2 O Brasil cada vez mais tem se articulado para garantir presença nas avaliações internacionais. Atualmente tem participado do "Programme for International Student Assessment" - Programa Internacional de Avaliação de Estudante (PISA), a Pesquisa Internacional sobre Ensino e Aprendizagem (TALIS) e o Terceiro Estudo Regional Comparativo e Explicativo (TERCE). O PISAé realizado a cada três anos de forma amostral, nas áreas de leitura, matemática e ciências. A TALIS contará em 2018 com a participação de 45 países. Ela ocorre a cada 5 anos e o Brasil participará pela terceira vez. Tem como foco o ambiente de aprendizagem e as condições de trabalho dos profissionais de educação básica. O público-alvo são as escolas que ofertam os anos finais do ensino fundamental e o ensino médio. Participam da pesquisa professores e diretores. $\mathrm{O}$ INEP é responsável de coordenar o PISA e a TALIS no Brasil. 
de resultados". Entres as principais questões levantadas estão a intensificação do trabalho docente, as políticas de premiação dos docentes e escolas por resultados nessas avaliações, o ranking entre escolas e a perpetuação das desigualdades educacionais.

Como exemplo desses processos de regulação educativa, no Brasil há o Sistema de Avaliação da Educação Básica (Saeb), que é constituído por um conjunto de avaliações externas em larga escala, permitindo ao Instituto Nacional de Pesquisas Educacionais Anísio Teixeira (Inep) realizar um diagnóstico da educação no país.

O Saeb é composto por meio de provas e questionários, aplicados periodicamente pelo Inep, possibilitando que os diferentes níveis governamentais avaliem a qualidade da educação ofertada no Brasil, oferecendo subsídios para a elaboração, monitoramento e aprimoramento das políticas educacionais.

O Saeb foi criado em 1990 e passou por algumas reestruturações. Atualmente compõem-se de: a) Avaliação Nacional da Educação Básica (Aneb); b) Avaliação Nacional do Rendimento Escolar (Anresc), conhecida como Prova Brasil e; Avaliação Nacional de Alfabetização (ANA). Atualmente todas essas avaliações são realizadas bianualmente. Os seus resultados são disponibilizados no portal do Inep.

Nosso foco neste artigo é a Anresc/Prova Brasil, pois, em razão das características metodológicas desse exame, nos permitirá compreender melhor o processo de regulação do trabalho em espaços rurais. Além disso, outro fator importante na escolha da Prova Brasil para nossa análise é que com base em seus resultados é possível calcular o Índice de Desenvolvimento da Educação Básica (Ideb) das escolas e dos municípios, bem como a construção de outros indicadores educacionais que permitem compreender melhor as diferentes particularidades da oferta da Educação Básica, em especial na zona rural no estado da Bahia.

A Avaliação Nacional do Rendimento Escolar (Anresc), também conhecida como Prova Brasil, é aplicada de forma censitária aos estudantes do $5^{\circ}$ e $9^{\circ}$ ano do ensino fundamental (escolas urbanas e rurais) regular das redes municipais, estaduais e federal. Somente as escolas que possuem no mínimo 20 alunos matriculados nos anos avaliados participam desta avaliação. Os resultados são disponibilizados por escola e por unidade federativa.

A edição de 2015 do Saeb foi regulamentada pela Portaria Inep $n^{\circ} 174$, de 13 de maio de 2015. As escolas que se enquadram em pelo menos uma das situações a seguir não têm resultados preliminares: 1) contar com menos de 20 alunos nas etapas avaliadas $\left(5^{\circ}\right.$ e $9^{\circ}$ do ensino fundamental e $3^{\circ}$ ano do ensino médio), conforme o Censo Escolar da Educação Básica de 2015 e; 2) escolas que não atingiram 50\% de participação do público-alvo na avaliação (BRASIL, 2015).

Por conta desse recorte metodológico (menos de 20 alunos nos anos avaliados) é que se torna necessário pensar a configuração das escolas rurais no contexto das avaliações em larga escala, pois é sabido que grande parte nas escolas rurais do país se configuram como multisseriadas e possuem poucos alunos matriculados, acarretando, por consequência, uma exclusão dessas avaliações.

Outro indicador que constitui as avaliações em larga escala no Brasil é o Índice de Desenvolvimento da Educação Básica (Ideb). O Ideb ${ }^{3}$ foi criado pelo Inep em 2007 e agrega em um só indicador dois conceitos igualmente importantes para a qualidade da educação: fluxo escolar e médias de desempenho nas avaliações. $\mathrm{O}$ indicador é calculado com base nos dados sobre aprovação escolar, obtidos no Censo Escolar, e médias de desempenho nas avaliações do Inep, o Sistema de Avaliação da Educação Básica (Saeb) para as unidades da Federação e para o país, e a Prova Brasil para os municípios.

Dito isso, algumas questões nos mobilizam para a escrita deste artigo, a saber: há diferenças na participação da Prova Brasil 2015 entre escolas urbanas e rurais no Território do Piemonte da Diamantina-Bahia? Como está configurada a participação das escolas rurais do Território do Piemonte da Diamantina-Bahia na Prova Brasil e Ideb 2015?

Utilizamos como metodologia para coleta de dados as bases oficiais disponibilizadas no site do Instituto Nacional de Pesquisas Educacionais Anísio Teixeira (Inep): os resultados da Prova Brasil

3 O Índice de Desenvolvimento da Educação Básica foi introduzido na política educacional pelo Lei ${ }^{\circ} 6.094$, de 24 de abril de 2007, o Plano de Metas Compromisso Todos pela Educação (BRASIL, 2007). 
$2015^{4}$ e do Ideb por escola. ${ }^{5}$

Dessa forma, seguimos os seguintes passos para identificar a participação na Prova Brasil e, posteriormente, as notas do Ideb das escolas rurais do território destacado: a) listamos todas as escolas públicas (urbanas e rurais) do território; b) no site do Inep, realizamos a pesquisa no Ideb Escola e identificamos as escolas públicas (urbanas e rurais) que realizaram a Prova Brasil 2015; c) no mesmo link do Ideb Escola coletamos a quantidade de escolas que não obtiveram nota do Ideb 2015, mesmo realizando a Prova Brasil e; d) por fim, organizamos uma lista com a quantidade de escolas públicas rurais que não alcançaram a meta prevista do Ideb 2015 e a quantidade de escolas que alcançaram as metas previstas para o Ideb 2015 e suas respectivas notas.

Diante desse cenário, nossa intenção é analisar a participação das escolas rurais do Território de Identidade do Piemonte da Diamantina-Bahia nas avaliações em larga escala, em particular na Prova Brasil 2015, e, consequentemente, a configuração de seus respectivos Ideb.

\section{O panorama da oferta da Educação Básica no Território do Piemonte da Diamantina-Bahia}

Consideramos importante apresentar um panorama geral de alguns indicadores acerca da educação em áreas urbanas e rurais do estado da Bahia e do Território de Identidade do Piemonte da Diamantina-Bahia.

No Brasil há 184.145 estabelecimentos de ensino, sendo que 67\% (123.451) e 33\% (60.694) encontram-se respectivamente nas zonas urbana e rural do país (INSTITUTO NACIONAL DE ESTUDOS E PESQUISAS EDUCACIONAIS ANÍSIO TEIXEIRA, 2018a). Ou seja, em dados gerais temos uma maior proporção de escolas no

4 O Inep divulga, a cada edição do Saeb, resultados agregados para os estratos Brasil, Unidades da Federação e Regiões, desagregados por dependência administrativa e localização. A partir de 2005, com a criação da Prova Brasil, municípios e escolas também passaram a ter seus resultados divulgados. A disponibilização dos resultados variou ao longo das edições entre relatórios consolidados, sistemas de acesso a resultados ou boletins de desempenho.

5 O Ideb Escola é o sistema de consulta pública e disseminação dos resultados do Ideb por unidade escolar, de maneira detalhada e comparável. espaço urbano, contudo sabemos que a depender da região geográfica do país essa proporção pode ser alterada.

O Censo Demográfico (INSTITUTO BRASILEIRO DE GEOGRAFIA E ESTATÍSTICA, 2010) apontou que o Brasil tinha $84 \%$ de sua população vivendo nas cidades e $16 \%$ na zona rural, logo a distribuição desigual das unidades escolares pelo território brasileiro apresenta sintonia com a densidade demográfica do país, que se caracteriza por apresentar em algumas regiões uma grande densidade demográfica, em especial nas cidades, nas capitais, nas regiões metropolitanas e nas cidades próximas da costa litorânea.

$\mathrm{Na}$ região Nordeste há 65.806 estabelecimentos de ensino que representa cerca de $35,7 \%$ das escolas brasileiras. Deste total, 32.850 (49,9\%) estão localizados no espaço urbano e 32.956 $(50,1 \%)$ na zona rural (INSTITUTO NACIONAL DE ESTUDOS E PESQUISAS EDUCACIONAIS ANÍSIO TEIXEIRA, 2018a). Os dados sobre os estabelecimentos de ensino da região Nordeste indicam leve diferença no quantitativo de escolas no contexto rural e no urbano, diferentemente do quadro nacional. Ou seja, essa inversão da proporção de unidades escolares que ocorre no Nordeste é fruto da disposição demográfica que se apresenta na região.

Especificamente no estado da Bahia percebemos que houve uma ampliação na diferença percentual de escolas rurais (52\%) em detrimento das escolas urbanas (48\%). Contudo, quando olhamos essa distribuição entre as esferas administrativas permanece ainda o que foi identificado no cenário nacional, em que há maioria de escolas na zona urbana nas esferas federal, estadual e privada.

Entretanto, o que mais chama atenção nos dados baianos é a diferença proporcional de escolas na esfera municipal, em que há 4.830 (34\%) na zona urbana e 9.061 (64\%) na zona rural. Portanto, a oferta da educação municipal no estado da Bahia é predominantemente rural.

Dito isso, apresentamos um panorama da educação rural no Território do Piemonte da Diamantina-Bahia. ${ }^{6}$ Este território de identidade é composto

\footnotetext{
6 De acordo com o Decreto $\mathrm{n}^{\circ} 15.806$, de 30 de dezembro de 2010, o Governo do Estado da Bahia dispõe sobre a organização territorial dos Núcleos Regionais de Educação (NRE), extinguindo as
} 
por nove (9) municípios: Caém, Jacobina, Miguel Calmon, Mirangaba, Ourolândia, Saúde, Serrolândia, Umburanas e Várzea Nova.

Apropriamos o conceito de Território segundo o Ministério do Desenvolvimento Agrário (MDA), o qual é conceituado como um espaço físico, geograficamente definido, geralmente contínuo, caracterizado por critérios multidimensionais, tais como o ambiente, a economia, a sociedade, a cultura, a política e as instituições, e uma população com grupos sociais relativamente distintos, que se relacionam interna e externamente por meio de processos específicos, onde se pode distinguir um ou mais elementos que indicam identidade, coesão social, cultural e territorial (BRASIL, 2003).

Essa noção de Território de Identidade tem se configurado como uma política de gestão do Governo do Estado da Bahia, e está amparada no
Decreto $\mathrm{n}^{\mathrm{o}} 12.354$, de 25 de agosto de 2010, ao reconhecer e definir a existência de 27 Territórios de Identidade no Estado da Bahia, constituídos a partir das especificidades de cada mesorregião (BAHIA, 2010a).

Destaca-se a amplitude do Território de Identidade do Piemonte da Diamantina, no que se refere a sua diversidade econômica, social, cultural e educacional. Compreendemos, também, que a efetivação da política territorial da Bahia apresenta-se de maneira dinâmica, por considerar processos de inserção e retirada de alguns municípios de determinados Territórios, através da política de reorganização administrativa do Estado.

De maneira sintética, o Gráfico 1 apresenta a distribuição da oferta da Educação Básica (matrículas, estabelecimentos de ensino, docentes e turmas) de acordo com a localização no Território investigado.

Gráfico 1 - Distribuição das turmas, estabelecimentos de ensino, docentes e matrículas na Educação Básica de acordo com a localização no Território do Piemonte da Diamantina-Bahia, 2017.

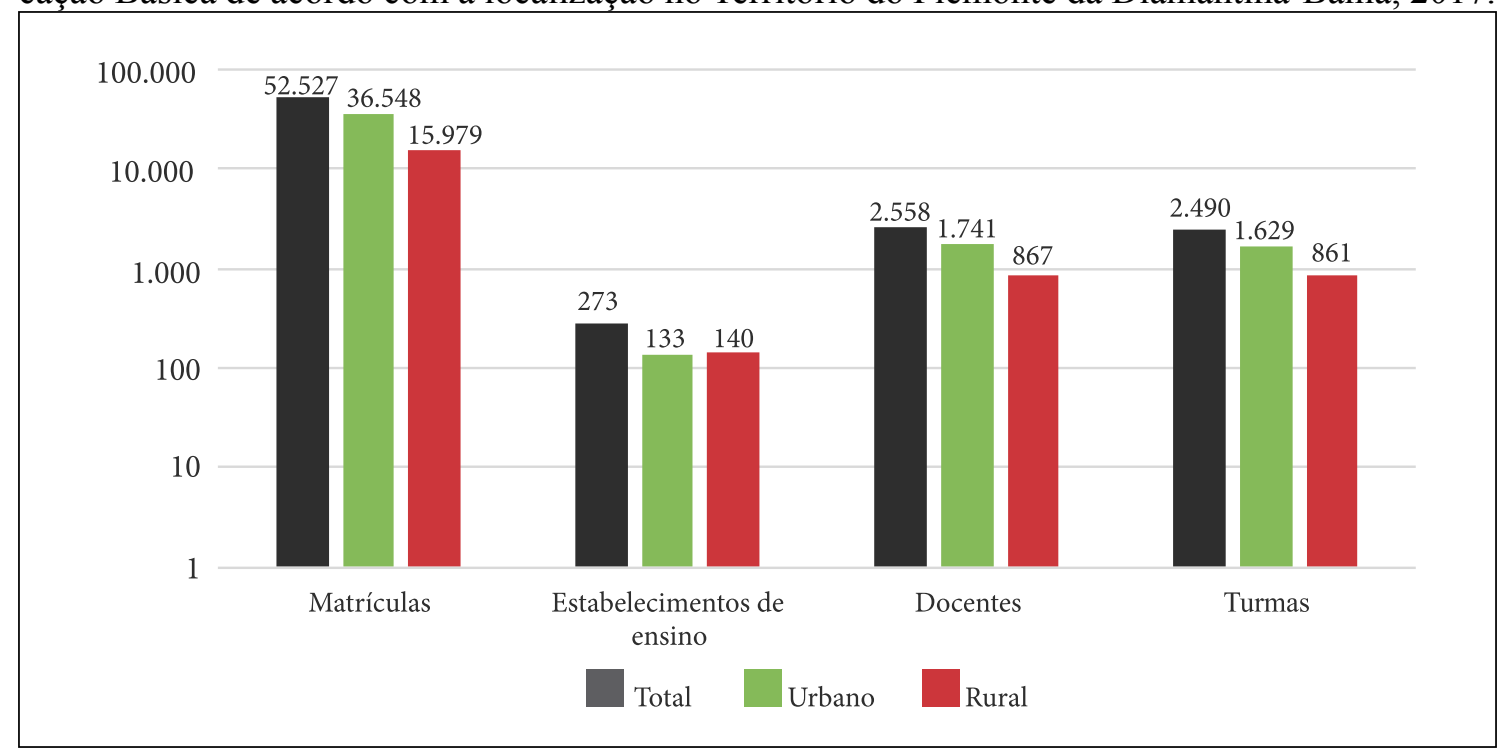

Fonte: Elaborada pelos autores deste artigo com base no Censo da Educação Básica 2017 (INSTITUTO NACIONAL DE ESTUDOS E PESQUISAS EDUCACIONAIS ANÍSIO TEIXEIRA, 2018a).

Diretorias Regionais de Educação (Direc). Essa nova organização acompanha a disposição da divisão por Territórios de Identidade no Estado da Bahia (BAHIA, 2010b). Atualmente contamos com 27 Núcleos Regionais de Educação (NRE). O Decreto no ${ }^{\circ} 17.377$, de 02 de fevereiro de 2017, altera as denominações e as finalidades de unidades administrativas da Secretaria da Educação do Estado da Bahia acarretando a modificação dos Núcleos Regionais de Educação (NRE) em Núcleos Territoriais de Educação (NTE) (BAHIA, 2017).
Portanto, na leitura dos dados acima, podemos perceber que a distribuição da oferta da Educação Básica no Território do Piemonte da Diamantina-Bahia se dá com predominância de matrículas, docentes e turmas na zona urbana. Contudo, há mais estabelecimentos de ensino na zona rural. 
Ampliando nosso olhar em relação aos estabelecimentos de ensino para os municípios que constituem o território, a Tabela 1 sistematiza a distribuição conforme a localização.

Tabela 1 - Distribuição dos estabelecimentos de ensino do Território do Piemonte da Diamantina de acordo com a localização, 2017

\begin{tabular}{|c|c|c|c|c|c|c|c|c|c|c|c|}
\hline \multicolumn{2}{|l|}{ MUNICÍPIOS } & \multicolumn{10}{|c|}{ ESTABELECIMENTOS DE ENSINO } \\
\hline & & \multicolumn{6}{|c|}{ URBANO } & \multicolumn{4}{|c|}{ RURAL } \\
\hline & $\underset{0}{\pi}$ & 胥 & 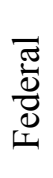 & 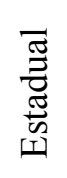 & 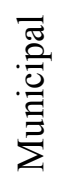 & $\underbrace{\frac{\pi}{\pi}}_{0}$ & 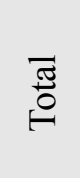 & 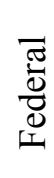 & 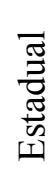 & 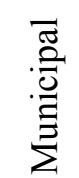 & 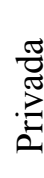 \\
\hline Caém & 17 & 6 & - & 1 & 4 & 1 & 11 & - & - & 11 & - \\
\hline Jacobina & 88 & 61 & 1 & 7 & 25 & 28 & 27 & - & - & 26 & 1 \\
\hline Miguel Calmon & 57 & 18 & - & 2 & 12 & 4 & 39 & - & - & 39 & - \\
\hline Mirangaba & 28 & 5 & - & 1 & 4 & - & 23 & - & - & 23 & - \\
\hline Ourolândia & 25 & 9 & - & 1 & 7 & 1 & 16 & - & - & 16 & - \\
\hline Saúde & 19 & 9 & - & 1 & 6 & 2 & 10 & - & - & 10 & - \\
\hline Serrolândia & 12 & 8 & - & 1 & 5 & 2 & 4 & - & - & 4 & - \\
\hline Umburanas & 13 & 7 & - & 1 & 4 & 2 & 6 & - & - & 6 & - \\
\hline Várzea nova & 14 & 10 & - & 1 & 6 & 3 & 4 & - & - & 4 & - \\
\hline Total & 273 & 133 & 1 & 16 & 73 & 43 & 140 & - & - & 139 & 1 \\
\hline
\end{tabular}

Fonte: Elaborada pelos autores deste artigo com base no Censo da Educação Básica 2017 (INEP, 2018a).

Sendo assim, vimos que em relação à quantidade de estabelecimentos de ensino no Território do Piemonte da Diamantina contamos com a seguinte disposição em ordem decrescente: Jacobina (88), Miguel Calmon (57), Mirangaba (28), Ourolândia (25), Saúde (19), Caém (17), Várzea Nova (14), Umburanas (13) e Serrolândia (12).

De acordo com a Tabela 1, há 273 escolas no Território do Piemonte da Diamantina-Bahia, distribuídas em 133 na zona urbana e 140 na zona rural. Identificamos que em Jacobina (61), Serrolândia (8), Umburanas (7) e Várzea Nova (10) há um predomínio de estabelecimentos de ensino na zona urbana. No entanto, nos municípios de Miguel Calmon (39), Mirangaba (23), Ourolândia (16), Saúde (10) e Caém (11) há um predomínio de estabelecimentos localizados na zona rural (INSTITUTO NACIONAL DE ESTUDOS E PESQUISAS EDUCACIONAIS ANÍSIO TEIXEIRA, 2018a).

Portanto, quando estabelecemos um comparativo com a dependência administrativa percebemos que tanto na zona rural como na urbana predominam estabelecimentos de ensino da rede municipal sobre a rede federal, privada e estadual. Contudo, em Jacobina, a quantidade de escolas urbanas da rede privada (28) é maior do que as outras redes administrativas. Outro destaque que chama atenção é que na zona rural há maioria absoluta de escolas municipais em todos os municípios, apenas em Jacobina existe uma escola privada rural (INSTITUTO NACIONAL DE ESTUDOS E PESQUISAS EDUCACIONAIS ANÍSIO TEIXEIRA, 2018a).

A maioria desses estabelecimentos de ensino oferta o ensino fundamental, seguido da educação infantil e ensino médio. Portanto, identificamos que esses dados apresentam sintonia com os dados estaduais e nacionais (INSTITUTO NACIONAL DE ESTUDOS E PESQUISAS EDUCACIONAIS ANÍSIO TEIXEIRA, 2018a).

A partir desse cenário e considerando investimentos empreendidos no desenvolvimento das pesquisas Multisseriação e trabalho docente: diferenças, cotidiano escolar e ritos de passagem (SOUZA, 2013, 2014), financiada pela Fundação de Amparo à Pesquisa do Estado da Bahia (Fapesb) e pelo Conselho Nacional de Desenvol- 
vimento Científico e Tecnológico (CNPq), e $A s$ políticas de educação e a reestruturação da profissão docente confrontadas aos desafios da globalização, financiada pela Fapesb é possível discutir cenários e questões relacionadas às condições de trabalho docente de professores que atuam em classes multisseriadas, bem como aprofundamento de aspectos concernentes aos diversos elementos da educação no espaço rural, notadamente no que diz respeito à formação docente, processos pedagógicos e de aprendizagem dos alunos de escolas, além de políticas voltadas para a educação rural e questões de infraestrutura das escolas. A escola rural não pode ser tratada de forma invisível, pois carece de um olhar que atenda às suas demandas específicas. Não podemos fechar os olhos para cerca de 140 escolas, 861 turmas, 867 docentes e 15 mil estudantes. Portanto, apresentamos no próximo tópico uma análise mais detalhada da participação dessas escolas na Prova Brasil 2015 e seus respectivos Índices de Desenvolvimento da Educação Básica (Ideb).

Esse movimento de jogar "luz" sob os aspectos da educação no espaço rural busca contribuir para o fortalecimento de políticas públicas e do trabalho docente nesses espaços, assim como a defesa e sen- tido da escola rural como espaço de formação das crianças, jovens e adultos em suas comunidades, além da escola configurar-se como um espaço de sociabilidade para as comunidades rurais.

\section{Prova Brasil 2015 e o Ideb das escolas rurais do Território do Piemonte da Diamantina-Bahia}

Intencionamos analisar a disposição da participação das escolas públicas rurais do Território do Piemonte da Diamantina-Bahia, ao tomarmos como referência resultados da Prova Brasil 2015 e do Ideb.

De acordo com o Censo Escolar de 2017, há 229 escolas públicas no território estudado, distribuídas em $139(60,7 \%)$ na zona rural e $90(39,3 \%)$ na zona urbana (INSTITUTO NACIONAL DE ESTUDOS E PESQUISAS EDUCACIONAIS ANÍSIO TEIXEIRA, 2018a). Portanto, neste território predomina a oferta de escolas rurais na educação básica pública. O Gráfico 2 apresenta a disposição das escolas públicas urbanas e rurais dos municípios do Território do Piemonte da Diamantina-Bahia na participação da Prova Brasil de 2015 e, consequentemente, na constituição do Ideb 2015.

Gráfico 2 - Distribuição da participação na Prova Brasil e Ideb 2015 dos municípios do Território do Piemonte da Diamantina-Bahia.

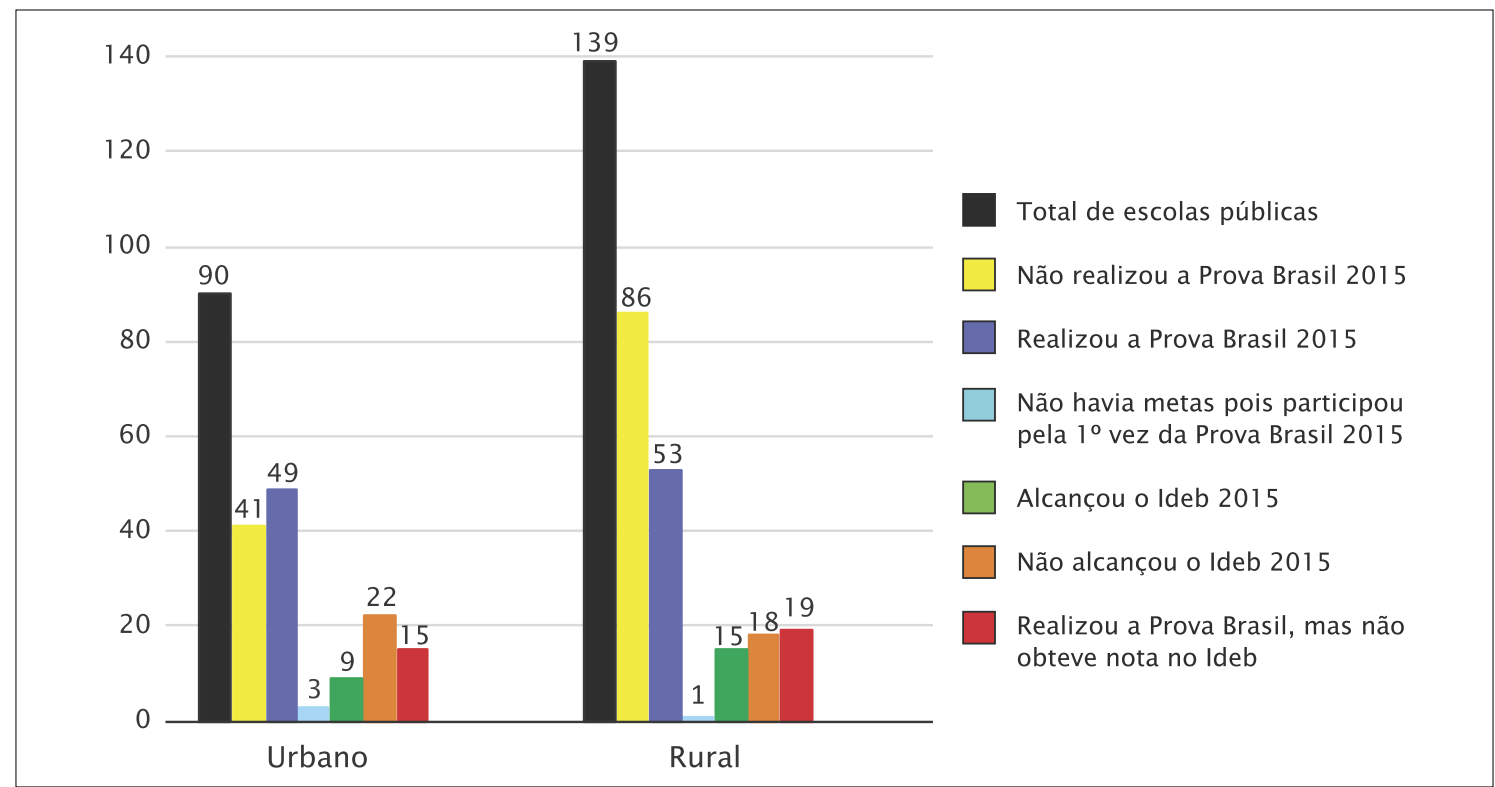

Fonte: Elaborada pelos autores deste artigo com base nos dados na plataforma Ideb Escola (INSTITUTO NACIONAL DE ESTUDOS E PESQUISAS EDUCACIONAIS ANÍSIO TEIXEIRA, 2018b). 
Da leitura do Gráfico 2 podemos extrair algumas informações importantes, que nos ajudam a compreender o processo de regulação do trabalho docente através da aplicação de avaliações em larga escala.

Quando comparamos o universo de escolas públicas rurais (139) e urbanas (90) do Território do Piemonte da Diamantina-Bahia, identificamos que $86(61,9 \%)$ das escolas rurais e $41(45,5 \%)$ das escolas urbanas não participaram desta da Prova Brasil 2015. Portanto, há uma maioria de escolas públicas rurais que não participaram dessa avaliação, apresentando uma diferença significativa em relação ao espaço urbano.

Esse dado é justificado em razão do recorte metodológico na aplicação da Prova Brasil, cujas turmas avaliadas $\left(5^{\circ}\right.$ e $9^{\circ}$ do ensino fundamental) devem ter no mínimo 20 alunos matriculados, e quando observamos o perfil de matrículas das referidas turmas na zona rural percebemos que grande parte não possuem a quantidade definida pelo Inep para aplicação da prova.

Dessa forma, cerca de $62 \%$ das escolas rurais do Território do Piemonte da Diamantina não realizaram a Prova Brasil 2015. Esse dado nos preocupa, pois um número significativo de unidades educacionais não terão condições de gerar a nota do Ideb e, consequentemente, não irão compor uma base de dados no país. Outro ponto que consideramos problemático é que os atores dessas escolas não avaliadas (estudantes, professores e diretores) não responderão ao questionário de contexto ${ }^{7}$ da Prova Brasil, que é uma importante ferramenta na coleta de dados e informações sobre diferentes aspectos da educação oferecida naquela localidade. Sendo assim, caso houvesse esse conjunto de informações, teríamos melhores condições de diagnósticos da realidade da educação rural e na proposição e aprimoramento das políticas públicas educacionais locais.

Outro ponto de destaque na leitura do Gráfico

7 Além da prova, os estudantes participantes, seus professores de língua portuguesa e matemática, e o diretor da escola, respondem a um questionário onde há questões sobre eles, sobre o ensino e sobre a escola. Esses questionários servem como instrumentos de coleta de informações sobre aspectos da vida escolar, do nível socioeconômico, capital social e cultural dos alunos. Os questionários realizados são ferramentas importantes para estabelecer um diagnóstico de como caminha a oferta da Educação Básica.
2 é a participação das escolas urbanas e rurais na Prova Brasil 2015. Sobre isso, extraímos algumas considerações. Ratificamos o que já era esperado em relação a uma menor quantidade de escolas rurais na obtenção do indicador do Ideb, pois encontramos que $37,8 \%$ das escolas urbanas obtiveram notas do Ideb 2015, em contrapartida a apenas $27 \%$ das escolas rurais que obtiveram o índice.

Outro dado que agrega ao que apontamos acima é que o percentual de escolas rurais $(35,9 \%)$ que participaram da Prova Brasil 2015 e não obtiveram os critérios mínimos para divulgação da nota do Ideb é maior do que as escolas urbanas (30,6\%).

Portanto, quando somamos as escolas que não participaram da Prova Brasil 2015 e as que participaram mas não obtiveram notas, percebemos que $78 \%$ das escolas rurais e $62,2 \%$ das escolas urbanas não possuem o Ideb 2015 no território investigado.

Em relação ao desempenho, percebemos que a maioria das escolas rurais (34\%) não alcançou o Ideb 2015, contudo o percentual é menor do que as escolas urbanas (45\%). E o percentual das escolas rurais $(28 \%)$ que alcançaram o Ideb 2015 é maior que o de escolas urbanas (18\%).

Dessa forma, encontramos um cenário diverso, em que devido aos recortes metodológicos do exame, há um grande número de escolas rurais que não participam e/ou não obtêm a nota do Ideb. Contudo, quando comparadas às escolas urbanas, as escolas rurais apresentam uma maior proporção que alcançaram as notas previstas do Ideb 2015 e uma menor proporção de estabelecimentos que não alcançaram as notas do Ideb 2015.

Todavia, compreendemos que a utilização do Ideb não pode ser o único indicador da qualidade da educação, pois, conforme aponta a literatura acadêmica, ${ }^{8}$ as escolas rurais historicamente sofrem com questões de infraestrutura, formação docente, materiais didáticos e políticas de valorização docente.

Quando olhamos mais detalhadamente para a distribuição das escolas rurais no Território do Piemonte da Diamantina-Bahia na participação da Prova Brasil 2015 e na obtenção do Ideb, encontramos o cenário descrito na Tabela 2.

8 Destacamos as pesquisas de Souza e colaboradores (2017a, 2017b); Amiguinho (2008); Rocha e Hage (2010); Hage (2005) e Souza $(2013,2014)$. 
Tabela 2 - Distribuição das escolas rurais dos municípios do território do Piemonte da Diamantina-Bahia na participação da Prova Brasil e Ideb 2015

\begin{tabular}{|c|c|c|c|c|c|}
\hline \multirow[t]{3}{*}{ Município } & \multirow{3}{*}{$\begin{array}{l}\text { Total de } \\
\text { escolas } \\
\text { rurais }\end{array}$} & \multirow{3}{*}{$\begin{array}{c}\text { Não } \\
\text { Participaram } \\
\text { da Prova } \\
\text { Brasil 2015 }\end{array}$} & \multicolumn{3}{|c|}{ Participaram da Prova Brasil 2015} \\
\hline & & & \multirow{2}{*}{$\begin{array}{c}\text { Não } \\
\text { obteve } \\
\text { Ideb } 2015\end{array}$} & \multicolumn{2}{|c|}{ Obteve Ideb 2015} \\
\hline & & & & $\begin{array}{l}\text { Alcançou } \\
\text { Ideb } 2015\end{array}$ & $\begin{array}{c}\text { Não Alcançou Ideb } \\
2015\end{array}$ \\
\hline Caém & 11 & 7 & 1 & 2 & 1 \\
\hline Jacobina & 26 & 15 & 3 & 6 & 2 \\
\hline Miguel Calmon & 39 & 32 & 2 & 1 & 4 \\
\hline Mirangaba & 17 & 13 & 3 & 4 & 3 \\
\hline Ourolândia & 15 & 9 & 1 & - & 5 \\
\hline Saúde & 13 & 11 & 1 & 1 & - \\
\hline Serrolândia & 4 & 1 & 2 & 1 & - \\
\hline Umburanas & 6 & - & 2 & 1 & 3 \\
\hline Várzea nova & 4 & - & 4 & - & - \\
\hline Total & 139 & 86 & 19 & 16 & 18 \\
\hline
\end{tabular}

Fonte: Elaborada pelos autores deste artigo com base nos dados da Plataforma Ideb Escola (INSTITUTO NACIONAL DE ESTUDOS E PESQUISAS EDUCACIONAIS ANÍSIO TEIXEIRA, 2018b).

Os dados da Tabela 2 nos apresentam o cenário específico das escolas rurais do Território do Piemonte da Diamantina-Bahia, e podemos afirmar que: a) $86(62 \%)$ das escolas rurais não realizaram a Prova Brasil 2015; b) 53 (38\%) das escolas rurais realizaram a Prova Brasil 2015; c) das escolas rurais que realizaram a Prova Brasil, $19(36 \%)$ não obtiveram nota; d) $16(30,25 \%)$ escolas rurais que realizaram a Prova Brasil alcançaram o Ideb previsto para 2015 e; e) $18(34,7 \%)$ escolas rurais avaliadas não alcançaram o Ideb previsto para 2015.

Portanto, observamos de imediato um grande número, cerca de $62 \%$ (86), de escolas rurais no território analisado que não participaram da Prova Brasil 2015, levando-nos a reforçar a crítica aos critérios metodológicos do exame, que excluem mais da metade das escolas rurais. Contudo, observamos ainda que a disposição das escolas rurais que não participaram da Prova Brasil se deu de forma dispersa no território do Piemonte da Diamantina-Bahia.
Ou seja, enquanto em Umburanas e Várzea Nova todas as escolas rurais participaram do exame, no restante dos municípios, com exceção de Serrolândia (com taxa de participação de $75 \%$ das escolas), a grande maioria dos estabelecimentos de ensino não realizaram a Prova Brasil. Desta forma, podemos perceber que em um pequeno cenário encontramos as diferenças e as desigualdades educacionais.

Quando olhamos para as escolas rurais que não obtiveram nota do Ideb, identificamos um cenário também diverso no território investigado. Destacamos três situações: a primeira no município de Várzea Nova, em que todas as escolas rurais avaliadas não conseguiram gerar a nota do Ideb; a segunda nos municípios de Serrolândia e Saúde, em que a maioria das escolas rurais, $50 \%$ e $66 \%$ respectivamente, não obtiveram as notas do Ideb; e, por fim, no restante dos municípios do Piemonte da Diamantina, em que no máximo um terço das escolas rurais obtiveram nota do Ideb. 
No que tange às escolas rurais que alcançaram o Ideb em 2015, o cenário analisado apontou que apenas em Caém, Jacobina e Saúde a maioria das escolas avaliadas conseguiram alcançar a meta prevista. Entretanto, nos municípios de Ourolândia e Várzea Nova nenhuma escola avaliada conseguiu alcançar a meta prevista.

Por fim, em relação às escolas rurais que não alcançaram o Ideb previsto para 2015, percebemos que o pior cenário é no município de Ourolândia, onde $83 \%$ das escolas não alcançaram a meta prevista. Nos municípios de Miguel Calmon e Umburanas, metade das escolas também não obtiveram o alcance da meta estipulada. Destaque positivo para os municípios de Saúde e Serrolândia, onde nenhuma escola rural avaliada ficou sem alcançar a meta do Ideb.

Conforme apresentamos anteriormente, que a participação na Prova Brasil é um dos elementos para a constituição do Ideb, consideramos oportuno apresentar de forma sintética (Tabelas 3 e 4) o quadro dos resultados do Ideb entre os anos de 2005 e 2017 para a rede pública (urbana e rural) dos municípios do território do Piemonte da Diamantina-Bahia. Ou seja, após apresentar o cenário específico das escolas rurais, exporemos como se configura o Ideb da rede pública (urbana e rural) do estado da Bahia e dos municípios que constituem o Território do Piemonte da Diamantina-Bahia.

Para a rede pública (urbana e rural) da Bahia, no $5^{\circ}$ ano do ensino fundamental, o Ideb saltou de 2,5 em 2007 para 4,7 em 2017. A rede pública estadual alcançou todas as metas entre os anos de 2007 e 2017 nesta etapa da educação básica. A meta para 2019 é 4,5 (INEP, 2018c).

No que tange ao território delimitado, desde a implementação do Ideb no ano de 2005 apenas os municípios de Jacobina e Várzea Nova conseguiram alcançar suas metas em todos os anos avaliados para o $5^{\circ}$ ano do ensino fundamental. Destacamos também que o município de Serrolândia não obteve o indicador no ano de 2007, contudo entre os demais anos avaliados conseguiram alcançar as metas previstas para esta etapa avaliada.

O município de Mirangaba, após não conseguir alcançar a meta no ano de 2009 , vem con- seguindo alcançar a meta prevista nas avaliações de 2011, 2013, 2015 e 2017. E o município de Umburanas apenas em 2017 não obteve o alcance da meta.

O cenário mais delicado para os anos iniciais do ensino fundamental, fica com os municípios de Caém, Miguel Calmon e Saúde, pois nos últimos 3 anos avaliados não conseguiram alcançar as metas previstas. Dessa forma, é necessário um alerta para os gestores na tentativa de melhorar as condições de oferta e, especialmente, no processo de aprendizagem dos alunos.

Outra etapa avaliada por nós foi os anos finais do ensino fundamental através dos resultados para o $9^{\circ}$ ano. A rede pública (urbana e rural) do estado da Bahia apresentou aumento do Ideb de 2005 à 2011, contudo nos anos de 2013, 2015 e 2017 o estado não conseguiu alcançar as metas previstas (INSTITUTO NACIONAL DE ESTUDOS E PESQUISAS EDUCACIONAIS ANÍSIO TEIXEIRA, 2018c).

Nessa etapa do ensino fundamental, desde a implementação do Ideb no ano de 2005, nenhum município do território analisado conseguiu alcançar as metas em todos os anos avaliados. Essa informação já apresenta onde devem ser concentrados os maiores esforços neste momento no âmbito das políticas educacionais locais.

Nos três primeiros anos avaliados (2007, 2009 e 2011), grande parte dos municípios garantiram o alcance das metas, contudo, nos três últimos anos (2013, 2015 e 2017), nenhum município, com exceção de Umburanas em 2015, conseguiu alcançar as metas desejadas.

Os resultados do município de Mirangaba nos chamam atenção, pois entre 2005 e 2017, mesmo apresentando aumento nas notas do Ideb, não conseguiu alcançar nenhuma meta prevista na avaliação.

Apenas Mirangaba, Serrolândia e Várzea Nova apresentaram aumento nas notas do Ideb entre os anos de 2015 e 2017, porém não foram suficientes para obtenção das metas previstas. Já os municípios de Caém, Jacobina, Miguel Calmon, Ourolândia, Saúde e Umburanas apresentaram declínio de suas notas entre as avaliações de 2015 a 2017 (Tabela 4). 
Tabela 3 - Distribuição do Ideb do $5^{\circ}$ ano do ensino fundamental (rede pública) do Território do Piemonte da Diamantina-Bahia

\begin{tabular}{cccccccc}
\hline & IDEB & IDEB & IDEB & IDEB & IDEB & IDEB & IDEB \\
& $\mathbf{2 0 0 5 *}$ & $\mathbf{2 0 0 7}$ & $\mathbf{2 0 0 9}$ & $\mathbf{2 0 1 1}$ & $\mathbf{2 0 1 3}$ & $\mathbf{2 0 1 5}$ & $\mathbf{2 0 1 7}$ \\
\hline Bahia & 2,5 & 3,2 & 3,5 & 3,9 & 3,9 & 4,4 & 4,7 \\
Caém & 2,6 & 2,7 & 3,7 & 3,9 & 3,7 & 4,1 & 4,6 \\
Jacobina & 2,8 & 3,6 & 3,6 & 3,9 & 3,9 & 4,4 & 4,9 \\
Miguel Calmon & 3,1 & 4,0 & 3,6 & 3,7 & 3,7 & 4,0 & 4,6 \\
Mirangaba & 2,2 & 2,9 & 2,7 & 4,0 & 4,2 & 4,4 & 4,6 \\
Ourolândia & 2,7 & 2,9 & 3,6 & 3,6 & 3,5 & 4,1 & 4,1 \\
Saúde & 2,0 & 2,6 & 2,6 & 3,4 & 3,2 & 3,4 & 4,1 \\
Serrolândia & 2,1 & - & 3,1 & 4,2 & 3,8 & 4,5 & 5,4 \\
Umburanas & 2,6 & 2,7 & 3,7 & 4,4 & 4,0 & 4,2 & 4,0 \\
Várzea Nova & 2,4 & 3,6 & 3,7 & 4,0 & 4,1 & 4,2 & 4,5 \\
\hline
\end{tabular}

Fonte: Elaborada pelos autores deste artigo com base nos dados da Plataforma Ideb resultados e metas (INSTITUTO NACIONAL DE ESTUDOS E PESQUISAS EDUCACIONAIS ANÍSIO TEIXEIRA, 2018c).

* Em 2005 foi o primeiro indicador do Ideb dos municípios, portanto não havia metas projetadas.

** Os resultados em cinza referem-se ao Ideb que atingiu a meta daquele ano.

Tabela 4 - Distribuição do Ideb do $9^{\circ}$ ano do ensino fundamental (rede pública) do Território do Piemonte da Diamantina-Bahia

\begin{tabular}{cccccccc}
\hline & IDEB & IDEB & IDEB & IDEB & IDEB & IDEB & IDEB \\
& $\mathbf{2 0 0 5 *}$ & $\mathbf{2 0 0 7}$ & $\mathbf{2 0 0 9}$ & $\mathbf{2 0 1 1}$ & $\mathbf{2 0 1 3}$ & $\mathbf{2 0 1 5}$ & $\mathbf{2 0 1 7}$ \\
\hline Bahia & 2,6 & 2,8 & 2,9 & 3,1 & 3,2 & 3,4 & 3,4 \\
Caém & 2,1 & 2,4 & 2,5 & - & 2,8 & 3,4 & 3,1 \\
Jacobina & 2,2 & 2,8 & 2,8 & 2,9 & 2,9 & 3,6 & 3,5 \\
Miguel Calmon & 2,8 & 3,1 & 2,8 & 3,1 & 3,4 & 3,0 & 2,9 \\
Mirangaba & 2,3 & 2,0 & 2,0 & 2,6 & 2,9 & 3,0 & 3,3 \\
Ourolândia & - & 2,8 & 3,3 & 3,3 & 2,9 & 3,3 & 3,2 \\
Saúde & 1,5 & 1,9 & 2,4 & 3,0 & 2,7 & 3,3 & 3,2 \\
Serrolândia & 1,7 & 2,3 & 2,9 & 2,9 & 3,0 & 3,0 & 3,1 \\
Umburanas & 2,0 & 2,7 & 3,3 & 3,6 & 3,0 & 3,5 & 3,3 \\
Várzea Nova & 2,0 & 2,7 & 3,1 & 3,0 & 3,0 & 3,4 & 3,6 \\
\hline
\end{tabular}

Fonte: Elaborada pelos autores deste artigo com base nos dados da Plataforma Ideb resultados e metas (INSTITUTO NACIONAL DE ESTUDOS E PESQUISAS EDUCACIONAIS ANÍSIO TEIXEIRA, 2018c).

* Em 2005 foi o primeiro indicador do Ideb dos municípios, portanto não havia metas projetadas.

** Os resultados em cinza referem-se ao Ideb que atingiu a meta daquele ano. 
Os dados das Tabelas 3 e 4 nos apontam para um cenário que merece uma atenção especial: as políticas educacionais tanto para o estado da Bahia quanto para os municípios do território analisado, tendo em vista que os resultados do $9^{\circ}$ ano do ensino fundamental apresentam um contexto que exigirá esforços na tentativa de melhorias da qualidade do ensino.

Consideramos que esse cenário justifica, ainda mais, a necessidade de análises mais específicas, tendo em vista as enormes desigualdades educacionais que encontramos no Brasil e no interior de seus estados e municípios.

Tais análises reforçam as discussões apresentadas por Alves e Soares (2013), quando afirmam sobre a necessidade de ampliação de estudos sobre os indicadores educacionais, nesse caso o Ideb, possibilitando considerar outras condições estruturantes para aferir a qualidade da educação básica do nosso país.

Alves e Soares (2013), partem do valor do Ideb no ano de 2009, ao tomarem as variáveis: a) nível socioeconômico da escola; b) proporção de alunos discriminados por raça/cor e por gênero; c) infraestrutura da escola e; d) tamanho e complexidade da escola. Em síntese, esses autores afirmam que o Ideb das escolas tem uma relação direta com o perfil dos alunos (nesse caso, escola com mais alunos negros tem a probabilidade em ter o Ideb menor), infraestrutura (nesse caso, quanto mais precária a infraestrutura, mais baixo será o Ideb) e o tamanho e complexidade (ou seja, quanto maior a escola e mais complexa, há probabilidade de ter o Ideb mais baixo).

Ainda sobre a discrepância entre o resultado do Ideb e a qualidade da educação oferecida, Alves e Soares (2013, p. 190) afirmam que:

Um sistema educacional só pode ser dito de qualidade se suas desigualdades são também consideradas na análise de seu desempenho. Os resultados descritos na seção anterior evidenciaram que a síntese da qualidade da escola em um único número não contempla as condições desiguais entre os estabelecimentos de ensino.

Ao analisarmos os indicadores educacionais no contexto do Estado da Bahia e do Território do Piemonte da Diamantina-Bahia, buscamos apro- ximações com os estudos de Cabral Neto, Souza e Queiroz (2013, p. 28), quando avaliam a situação do Ideb do Estado do Rio Grande do Norte, ao afirmarem que:

Esses indicadores educacionais evidenciam a fragilidade do ensino público [...] e, também, são ilustrativos da incapacidade do governo de adotar políticas capazes de alterar o quadro caótico da educação, principalmente, mas não exclusivamente, no que concerne à qualidade de ensino.

Ao dialogarmos com Cabral Neto, Souza e Queiroz (2013) podemos perceber que existem vizinhanças e aproximações na comparação dos dados educacionais, o que provavelmente representa um descaso histórico que foi implementado pelos governos nos processos educacionais dos estados da região Nordeste do Brasil.

Dessa forma, em que pese o Brasil, a Bahia e o território investigado ainda não terem conseguido superar diversos abismos e suas desigualdades educacionais, é fundamental a ampliação de investimentos em políticas educacionais e o cumprimento do plano (nacional, estadual e municipal) de educação para melhorar a qualidade da escola pública.

Contudo, consideramos necessário um certo cuidado com a apropriação indébita desses dados pois, conforme Freitas (2018) em seu blog Avaliação Educacional, podem induzir a "uma situação de caos na educação brasileira que não corresponde à realidade". Isso se justifica para aglutinar esforços nos projetos de reformas educativas, dentre elas a Reforma do Ensino Médio que atualmente está tramitando no país, bem como pode servir para atender aos interesses privados, criando a falsa noção de que as escolas privadas têm mais qualidade do que as públicas, fundamentando propostas e ações que podem entregar a gestão de escolas públicas à esfera privada, a adoção de kits padronizados de grupos editoriais e até a implementação de vouchers às famílias mais pobres para matricular seus filhos em escolas particulares.

\section{Considerações finais}

Reafirmamos, baseados no debate posto sobre o Ideb, que a instituição escolar precisa voltar-se para sua função social central, que é o aprendizado 
dos alunos, mas também o reconhecimento de seus múltiplos aspectos e das condições contextuais em que as escolas estão inseridas, garantindo também melhores condições de trabalho para os docentes.

Vimos que os resultados entre as escolas rurais que realizaram a Prova Brasil 2015 foram muito próximos entre aquelas que não obtiveram nota, aquelas que obtiveram o alcance das metas e as que não obtiveram o alcance das metas.

$\mathrm{O}$ dado que mais chama atenção em nossa coleta é a grande quantidade de escolas rurais que não realizam a Prova Brasil e que não possuem Ideb. Conforme já apontamos, como grande parte dessas escolas rurais não participaram dos exames, consequentemente não é construído um banco de dados que possa servir para pesquisa e refiguração das políticas educacionais locais.

Consideramos importante outros estudos que visem a uma análise mais específica sobre o Ideb dessas escolas rurais e que possam identificar, com base em outros indicadores, o contexto em que acontece a oferta dessa educação básica, possibilitando, assim, uma reflexão mais contextualizada, por exemplo, analisar a partir do boletim de desempenho de cada escola o perfil do nível socioeconômico das escolas, o perfil da formação docente nessas escolas, o percentual de alunos que participaram da avaliação e suas respectivas proficiências em língua portuguesa e matemática.

É necessário também apontar a importância de outros estudos que visem a análises sobre o impacto dessas regulações educativas sobre as condições de trabalho dos professores, sua formação, suas estratégias cotidianas relacionadas ao processo de aprendizagem dos alunos, dentre outros aspectos que incidirão direta e indiretamente sobre o processo de ensino e aprendizagem nos espaços escolares.

Portanto, ao apontar alguns indicadores educacionais do Estado da Bahia e do Território do Piemonte, temos o entendimento que os dados apontam para um cenário educacional que exige urgência e necessidade de que os avanços se deem de forma mais eficaz. Dessa forma, entendemos que caso não enfrentemos de maneira séria e com qualidade a realidade da educação pública de nosso país, haverá cada vez mais a precarização das condições do trabalho docente.

\section{REFERÊNCIAS}

AFONSO, Almerindo Janela. Nem tudo o que conta em Educação é mensurável ou comparável. Crítica à accontabillity baseada em testes estandardizados e rankings escolares. Revista Lusófona de Educação, v. 13, n. 13, p. 13-29, jul. 2009. Disponível em: <http://revistas.ulusofona.pt/index.php/rleducacao/article/view/545>. Acesso em: 13 set. 2018.

ALVES, Maria Teresa Gonzaga; SOARES, José Francisco. Contexto escolar e indicadores educacionais: condições desiguais para a efetivação de uma política de avaliação educacional. Educação e Pesquisa. São Paulo, v. 39, n. 1, p. 177-194, jan./mar. 2013. Disponível em: <http://www.scielo.br/pdf/ep/v39n1/v39n1a12.pdf>. Acesso em: 10 set. 2018.

AMIGUINHO, Abílio. Escola em meio rural: uma escola portadora de futuro? Educação, Santa Maria, RS, v. 33, n. 1, p. 11-32, jan./abr. 2008. Disponível em: $<$ https://periodicos.ufsm.br/reveducacao/article/view/16/28>. Acesso em: 08 nov. 2018.

AUGUSTO, Maria Helena. Regulação educativa e trabalho docente em Minas Gerais: a obrigação de resultados. Educação e Pesquisa, São Paulo, v. 38, n. 3, p. 695-709, jul./set. 2012. Disponível em <http://www.scielo.br/ scielo.php?pid=S1517-97022012000300011\&script=sci_abstract\&tlng=es $>$. Acesso em: 13 set. 2018 .

BAHIA. Decreto $\mathbf{n}^{\mathbf{0}} \mathbf{1 2 . 3 5 4}$, de 25 de agosto de 2010. Institui o Programa Territórios de Identidade e dá outras providências. Salvador, 2010a. Disponível em: <https://governo-ba.jusbrasil.com.br/legislacao/1024959/decreto-12354-10>. Acesso em: 28 nov. 2018.

Decreto $\mathbf{n}^{\mathbf{0}} \mathbf{1 5 . 8 0 6}$, de 30 de dezembro de 2010. Dispõe da organização territorial dos Núcleos Regionais de Educação, e dá outras providências. Salvador, 2010b. Disponível em: < http://www.educacao.ba.gov.br/system/ files/private/midiateca/.../decreto-no-15806.pdf>. Acesso em: 26 maio 2018.

Decreto $\mathbf{n}^{0}$ 17.377, de 02 de fevereiro de 2017. Altera as denominações e as finalidades das unidades ad- 
ministrativas da Secretaria da Educação e dá outras providências. Salvador, 2017. Disponível em: <http://diarios. egba.ba.gov.br/html/DO02/fotos/executivo.pdf>. Acesso em: 10 set. 2018.

BARROSO, João. Regulação e desregulação nas políticas educativas: tendências emergentes em estudos de educação comparada. In: BARROSO, João (Org.). A escola pública: regulação, desregulação, privatização. Porto: Asa, 2003. p. 19-48.

BRASIL. Presidência da República. Casa Civil. Lei no 6.094, de 24 de abril de 2007. Dispõe sobre a implementação do Plano de Metas Compromisso Todos pela Educação, pela União Federal, em regime de colaboração com Municípios, Distrito Federal e Estados, e a participação das famílias e da comunidade, mediante programas e ações de assistência técnica e financeira, visando a mobilização social pela melhoria da qualidade da educação básica. Brasília, DF: MEC, 2007. Disponível em: <http://www.planalto.gov.br/ccivil_03/_ato2007-2010/2007/decreto/ d6094.htm>. Acesso em: 27 mai. 2018.

Ministério do Desenvolvimento Agrário. Referências para o desenvolvimento territorial sustentável. Brasília: CONDRAF/NEAD, 2003.

Portaria $\mathrm{n}^{\circ}$ 174, de 13 de maio de 2015. Diário Oficial da União, Poder Executivo, Brasília, DF, 14 maio 2015. Seção 1, p. 16. Disponível em: <http://download.inep.gov.br/educacao_basica/prova_brasil_saeb/legislacao/2015/portaria_n174_13052015.pdf>. Acesso em: 12 set. 2018.

CABRAL NETO, Antônio; SOUZA, Antônio Lisboa Leitão de; QUEIROZ, Maria Aparecida de. Dimensões da realidade educacional do Rio Grande do Norte. In: CABRAL NETO, Antonio, OLIVEIRA, Dalila Andrade, VIEIRA, Lívia Fraga (Org.) Trabalho docente: desafios no cotidiano da educação básica. Campinas, SP: Mercado de letras, 2013. p. 25-62.

FREITAS, Luiz Carlos de. Blog do Freitas. INEP: produzindo o fracasso escolar. 04 set. 2018. Disponível em: $<$ https://avaliacaoeducacional.com/2018/09/04/inep-produzindo-o-fracasso-escolar/>. Acesso em: 08 nov. 2018.

HAGE, Salomão Mufarrej. Escola do campo na Amazônia: retratos de realidade das escolas multisseriadas no Pará. Belém: Gutemberg, 2005.

INSTITUTO BRASILEIRO DE GEOGRAFIA E ESTATÍSTICA (IBGE). Censo Demográfico de 2010. Rio de Janeiro, 2010. Disponível em: <https://ww2.ibge.gov.br/home/estatistica/populacao/censo2010/default.shtm>. Acesso em: 10 set. 2018.

INSTITUTO NACIONAL DE ESTUDOS E PESQUISAS EDUCACIONAIS ANÍSIO TEIXEIRA(Inep). Panorama da educação no campo. Brasília, DF, 2007. Disponível em: <http://portal.inep.gov.br/informacao-da-publicacao/-/ asset_publisher/6JYIsGMAMkW1/document/id/490919>. Acesso em: 12 set. 2018.

. Sinopse Estatística da Educação Básica 2017. Brasília, DF, 2018a. Disponível em: <http://portal.inep.

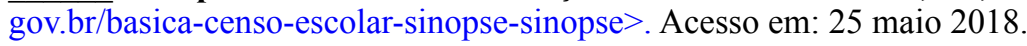

Prova Brasil. Avaliação do Rendimento Escolar: resultados finais. Brasília, DF, 2018b. Disponível em:

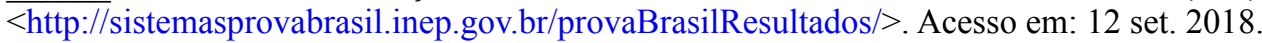

Índice de Desenvolvimento da Educação Básica - Ideb: resultados e metas. Brasília, DF, 2018c. Disponível em: <http://ideb.inep.gov.br/>. Acesso em: 12 set. 2018.

OLIVEIRA, Dalila Andrade. A reestruturação do trabalho docente: precarização e flexibilização. Educação \& Sociedade, Campinas, SP, v. 25, set./dez. 2004. Disponível em: <http://cedes.unicamp.br>. Acesso em: 11 set. 2018.

PESQUISA NACIONAL POR AMOSTRA EM DOMICÍLIO (Pnad). Síntese de Indicadores 2015. Rio de Janeiro: IBGE, 2016. Disponível em: <http://www.ibge.gov.br>. Acesso em: 12 maio 2018.

ROCHA, Maria Isabel Antunes; HAGE, Salomão Mufarrej. Escola de direito: reinventando a escola multisseriada. Belo Horizonte: Autêntica, 2010.

SOUZA, Elizeu Clementino de (Coord.). Multisseriação e trabalho docente: diferenças, cotidiano escolar e ritos de passagem. Projeto apresentado à FAPESB no âmbito do Edital 028/2012. Salvador: UNEB/FAPESB, 2013.

(Coord.). Multisseriação e trabalho docente: diferenças, cotidiano escolar e ritos de passagem. Projeto de Pesquisa apresentado ao Conselho Nacional de Desenvolvimento Científico e Tecnológico, no âmbito no âmbito da Chamada Universal - MCTI/CNPq n. 14/2014. Salvador: UNEB, 2014. 
SOUZA, Elizeu Clementino de. Et. al. Escola rural: diferenças e cotidiano escolar. Salvador: EDUFBA, 2017 a. (Caderno temático 2).

. Multisseriação, seriação e trabalho docente. Salvador: EDUFBA, 2017b. (Caderno temático 1).

Recebido em: 30/06/2018

Aprovado em: 29/08/2018 